\title{
Corticosteroids used in dermatology: its utilisation and cost analysis study
}

\author{
Vijaykumar Lakshman Lamani, Aruna Bhushan*
}

Department of Pharmacology, BIMS, Belagavi, Karnataka, India

Received: 23 July 2016

Accepted: 28 August 2016

*Correspondence to:

Dr. Aruna Bhushan,

Email: arunamarina@

yahoo.co.in

Copyright: (C) the author(s), publisher and licensee Medip Academy. This is an openaccess article distributed under the terms of the Creative Commons Attribution NonCommercial License, which permits unrestricted noncommercial use, distribution, and reproduction in any medium, provided the original work is properly cited.

\begin{abstract}
Background: Drug utilization studies are powerful exploratory tools to ascertain the role of drugs in the society; they create a sound socio-medical and health economics basis for making health care decision. The study focuses on factors related to prescribing, dispensing and administration of medication. The objective was to study prescribing pattern, duration of treatment and rationality of corticosteroids used in dermatology department and to evaluate the cost analysis of prescription.
\end{abstract}

Methods: A non-interventional prospective study was done in dermatology department for one and a half year. 807 inpatient and outpatient prescriptions with corticosteroids were collected. The data collected was expressed in terms of averages, ratios and proportions.

Results: Out of 807 patients, 300 were male and 507 females. Total number of drugs prescribed was 2231, with average number per prescription being 2.76. Drugs prescribed by generic name $69.3 \%$ remaining $30.7 \%$ were brand names. Total of $75.1 \%$ were prescribed from essential drug list. $65.1 \%$ were dispensed from hospital pharmacy and $34.9 \%$ from outside pharmacy and betamethasone was the most prescribed corticosteroid. In our study average cost of prescription was 167.72 INR. The average cost of corticosteroids per prescription was 42.87 INR and average cost of other drug prescribed with corticosteroids was 124.87 INR.

Conclusions: Use of corticosteroids drugs was found to be appropriate as per standard guidelines.

Keywords: Dermatology, Drug use, Corticosteroids, Cost analysis

\section{INTRODUCTION}

Drug use is a complex process. In any country a large number of socio-cultural and other factors contribute to the ways the drugs are used. In India, these includes national drug policy, illiteracy, poverty, use of multiple health care systems, drug advertising and promotion, sale of prescription drugs without prescription, competition in the medical and pharmaceutical market place and limited availability of independent, unbiased drug information. Inappropriate drug use leads to increased cost of medical care, antimicrobial resistance, adverse effects and patient mortality. Irrational prescription of drugs is a common occurrence in clinical practice. ${ }^{1}$ The cost of such irrational drug use is enormous they also have adverse clinical consequences of therapies that may have real risks but no objective benefits. ${ }^{2}$ Hence in recent years, studies on drug utilization have become a potential tool to be used in the evaluation of health systems. ${ }^{3}$

Dermatology is one of the few disciplines in which we are able to apply therapy directly to the target site. The drugs commonly used in dermatology are vitamins/minerals, antibiotics, antiseptics, antifungal, antiviral, antihistamines, emollients, keratolytics and corticosteroids. ${ }^{4}$ The use of corticosteroids started many decades ago as they are very powerful anti-inflammatory agents, and were described as impressive drugs as they not only improved certain clinical conditions, but also conferred a subjective sense of well-being. The topical corticosteroids (TC) are among the most commonly prescribed medication in dermatology setting since they were first introduced in early $1950 \mathrm{~s}^{5-7}$ TC have revolutionized the practice of dermatology and they still 
constitute one of the largest groups of drugs used in this discipline.

Collection of data on the utilization of drugs at the hospital level has been shown to be an effective tool to constitute guidelines for improving drug utilization patterns. This has resulted in more effective and rational therapy as well as economic benefits in the use of drugs. ${ }^{8}$ As per our knowledge, very few systematically analysed data are available on the drug utilization study pattern in dermatology in India.

The present study was undertaken in patients taking treatment in the dermatology department of the teaching hospital to generate baseline drug use data and analyse various aspects of drug prescribing practices. To obtain detail information on the number of drugs prescribed, their prescribing patterns, the duration of treatment and rationality of drug use in dermatology department and to evaluate the cost analysis of corticosteroid prescribed.

\section{METHODS}

A prospective observational study was done in the department of dermatology, Belgaum Institute of Medical Sciences, Belgaum. After obtaining approval and clearance from the Institutional Ethics Committee a total of 807 outpatient and inpatient prescription records with corticosteroids were collected for a period of one and a half year. The patients those who fulfilled inclusion and exclusion criteria were included in our study. Inclusion criteria: All age group of either sex prescribed with corticosteroid in dermatology department during study period. Exclusion criteria were prescriptions which did not contain corticosteroid and pregnant and lactating mothers.

The data collected by direct observation were entered in a specially designed proforma containing relevant detail such as demographic, disease and drug data. All these patients were followed up during their hospital stay and subsequent follow up.

\section{Statistical methods}

Descriptive and inferential statistical analysis has been carried out in the present study. Data was analysed on software using SAS 9.2 and R environment ver.2.11.1. Microsoft word and excel to generate graphs, tables etc. have been used.

\section{RESULTS}

In our prospective study the following results were obtained. Inflammatory skin diseases affect men, women and children of all ages. Amongst 807, highest number of patients was of age group of 31-40 year (198) as shown in the Figure $1.300(37.2 \%)$ were females and $507(62.8 \%)$ were males. 102 inpatient prescription were collected and
705 prescription of patient visiting dermatology OPD during the study period.

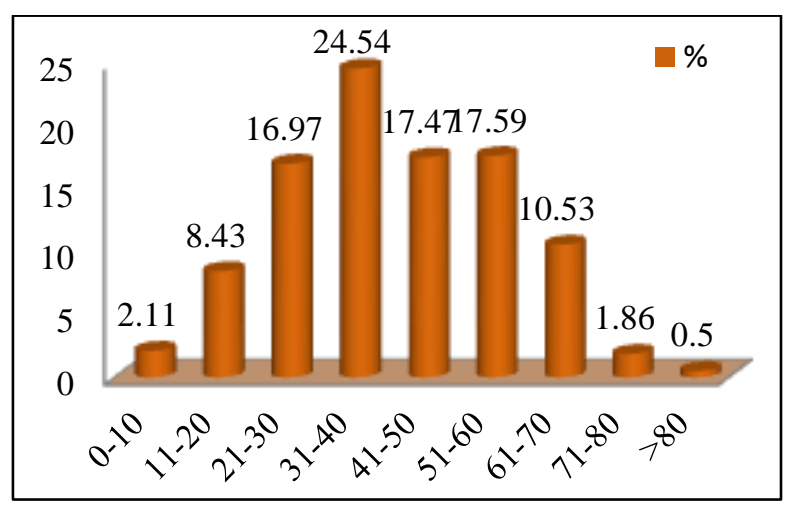

Figure 1: Age wise distribution of patients.

\section{Drug data}

Total 889 corticosteroid formulation were prescribed in our study populations, around 471 (53\%) of these formulations consisted of betamethasone which was commonly prescribed, 48 formulations consisted of prednisolone and $8(0.9 \%)$ fluticasone and only two formulation consisted fluocinolone $(0.2 \%)$ shown in Figure 2.

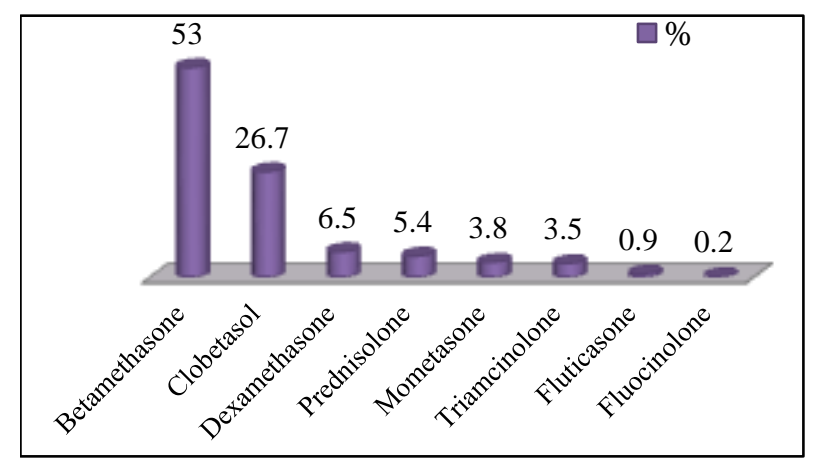

Figure 2: Type of corticosteroids drugs prescribed to the patients.

Corticosteroids are prescribed in different formulations and different routes of administration in dermatology department. Out of 889 formulation, most of the patients receiving corticosteroids were prescribed with topical preparation consisted of $760(85.5 \%)$, oral preparation were $51(5.7 \%)$ and 29 were intravenous route corticosteroid preparations, 26 were through intramuscular and 23 were intra lesion routes.

Other concomitant drug prescribed to patient for symptomatic relief and prophylactic to reduce adverse drug reaction were antihistaminics 654, antacids 104, liquid paraffin, systemic antibiotics, antibiotic creams, calcium preparations, multivitamins and other drugs shown in (Table 1). 
Table 1: Concomitant drugs prescribed with corticosteroid.

\begin{tabular}{|lll|}
\hline Other drugs prescribed & No. of patients & $\%$ \\
\hline Antihistaminics & 654 & 48.73 \\
\hline Others & 165 & 12.30 \\
\hline Antacids & 104 & 7.75 \\
\hline Liquid paraffin & 93 & 6.93 \\
\hline Antibiotics & 61 & 4.55 \\
\hline Calcium preparation & 53 & 3.95 \\
\hline Sun screen & 39 & 2.91 \\
\hline Multivitamins & 37 & 2.76 \\
\hline Antibiotic creams & 27 & 2.01 \\
\hline Cyclophosphamide & 25 & 1.86 \\
\hline Iron preparations & 24 & 1.79 \\
\hline Calamine lotion & 17 & 1.27 \\
\hline Paracetamol & 10 & 0.75 \\
\hline Antihypertensives & 8 & 0.60 \\
\hline Hypoglycemic & 7 & 0.52 \\
\hline Methotrexate & 5 & 0.37 \\
\hline Chlorhexidine & 4 & 0.30 \\
\hline Azathioprine & 3 & 0.22 \\
\hline Clotrimazole & 2 & 0.15 \\
\hline Fluconazole & 2 & 0.15 \\
\hline Thalidomide & 1 & 0.07 \\
\hline Thyroxine & 1 & 0.07 \\
\hline Total & 1342 & 100 \\
\hline
\end{tabular}

The common skin conditions encountered in the Dermatology where corticosteroids used were eczematous diseases like allergic contact dermatitis (ACD) about 149 (18.46\%), chronic eczema 62 (11.7\%), infective dermatitis 40(4.96), irritant contact dermatitis (ICD) about $27(3.35 \%)$ other papillosquamous diseases like psoriasis and bullous dermatoses, auto immune skin diseases and other diseases as shown in Figure 3 and diseases of less than $2.25 \%$ prescribed with corticosteroid is shown in the (Table 2).

Analysis of prescriptions of patients with respect to different parameters: The total number of drugs prescribed in the 807 prescriptions was 2231 with the average number of drugs per prescription being 2.76 . Drugs prescribed by generic name $1545(69.3 \%)$ and the remaining brand names, 1675 were prescribed from essential drug list. Most of the prescribed drugs were dispensed from hospital pharmacy "Fig. 4". The polypharmacy found in the prescriptions were $9.9 \%$.

Cost analysis of prescriptions: The average cost of prescription was ₹ 167.72 (Table-3). The average cost of corticosteroid per prescription was ₹ 42.87 and average cost of other drug prescribed with corticosteroids was ₹ 124.87 (Table-4). In this study Unit cost of drugs prescribed per patient was calculated. However actual direct costs and indirect costs were not taken into consideration for cost analysis.
Table 2: Other diseases with < than $2.25 \%$ prescribed with corticosteroid.

\begin{tabular}{|lll|}
\hline Lichen planus & $\mathbf{1 8}$ & $\mathbf{2 . 2 3}$ \\
\hline Keratoderma & 15 & 1.86 \\
\hline Discoid eczema & 14 & 1.73 \\
\hline Alopecia aerata & 10 & 1.24 \\
\hline Bullous pemphigoid & 9 & 1.12 \\
\hline Lepra type 2 reaction & 9 & 1.12 \\
\hline Drug hypersensitivity & 7 & 0.87 \\
\hline Sle & 7 & 0.87 \\
\hline Scalp psoriasis & 5 & 0.62 \\
\hline Erythema multiforme & 4 & 0.50 \\
\hline Guttate psoriasis & 4 & 0.50 \\
\hline Seborrheic dermatitis & 4 & 0.50 \\
\hline Sjs syndrome & 4 & 0.50 \\
\hline Fixed drug eruption & 3 & 0.37 \\
\hline Pompholyx & 3 & 0.37 \\
\hline Drug rash & 2 & 0.25 \\
\hline Mctd & 2 & 0.25 \\
\hline Systemic sclerosis & 2 & 0.25 \\
\hline Pitrysis lichenoid & 1 & 0.12 \\
\hline Ten & 1 & 0.12 \\
\hline Vasculitis & 1 & 0.12 \\
\hline
\end{tabular}

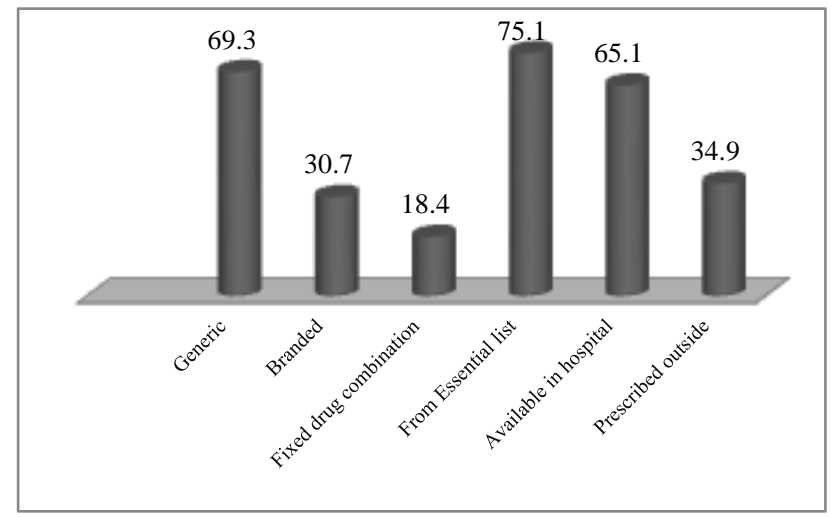

Figure 4: Analysis of dispensing pattern of drugs.

Table 3: Cost analysis of total prescribed drug.

\begin{tabular}{|ll|}
\hline Total cost of drug & $\mathbf{1 3 5 3 5 0 . 7}$ \\
\hline No. of. prescription & 807 \\
\hline Average cost per prescription & 167.7208 \\
\hline
\end{tabular}

Table 4: Cost analysis of corticosteroid prescribed.

\begin{tabular}{|lll|}
\hline Drugs & $\begin{array}{l}\text { Corticosteroid } \\
\text { drugs }\end{array}$ & Other drugs \\
\hline $\begin{array}{l}\text { Average cost per } \\
\text { prescription }\end{array}$ & 42.87 & 124.85 \\
\hline$\%$ & 25.56 & 74.44 \\
\hline Total & 167.72 & 100 \\
\hline
\end{tabular}


$\square \%$

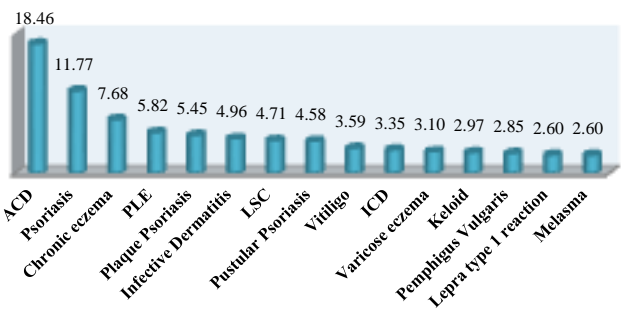

Figure 3: Diseases prescribed with Corticosteroids in dermatology department.

\section{DISCUSSION}

Corticosteroids play a major role in the dermatologist's armamentarium. Since the discovery of corticosteroids (glucocorticoids) in the 1940s and the recognition of their anti-inflammatory effects. It is most widely used in treatment of dermatological diseases to control inflammatory and autoimmune conditions. Further development of topical corticosteroids has enabled many dermatoses to be more effectively treated. ${ }^{9}$ In our study, demographic data showed that majority of patients were middle aged group which is similar to the study done by Divyashanti CM et al. ${ }^{10}$ Out of 807 patients $300(37.2 \%)$ were females and $507(62.8 \%)$ were males similar to study done by Bejoy KP et al. ${ }^{11}$ This shows skin diseases affects people of all ages.

In our study, most common skin conditions encountered were eczematous diseases like allergic contract dermatitis (ACD) $18.46 \%$ chronic eczema $11.7 \%$, infective dermatitis $4.96 \%$, irritant contract dermatitis (ICD) $3.35 \%$ other papillosquamous diseases like psoriasis vulgaris $11.7 \%$, plaque psoriasis $5.45 \%$, pustular psoriasis $4.58 \%$ and bullous dermatoses includes pemphigus vulgaris $2.85 \%$, bullous pemphigoid $1.12 \%$ auto immune skin diseases and other diseases. This disease pattern was similar to the study conducted by Mirshad PV et al., Kumar AM et al. and Kuruvilla $\mathrm{M}$ et al. which also showed that eczematous disease were most common. ${ }^{12-14}$ These incidences of skin diseases rely mostly on the geographic location, genetic makeup and other environmental factors. ${ }^{15}$

In our study, we observed that corticosteroids were prescribed in different formulations and different routes in dermatology. Most of the patients were prescribed with topical corticosteroid preparation $85.5 \%$. It is very high compared to similar study done by Jena $\mathrm{M}$ et al. and Rathod SS et al. which showed $67 \%$ and $43 \%$ respectively. ${ }^{16,17}$ The reason for high percentage of topical drugs being prescribed in our study was that topical route has minimum side effects as compared to systemic routes of drug administration. It was also observed that the frequency of administration and site of application were specified in the majority of the prescription of topically administered drugs but dose/strength of topical preparations were specified in only few prescriptions. Not specifying the quantity can result in under usage of the preparation causing subsequent sub-therapeutic outcome, at the same time excessive usage can result in unwanted effects. A total number of 889 corticosteroids were prescribed in the 807 prescriptions analyzed and the average number of corticosteroids per prescription was found to be 1.10 similar study conducted by Mirshad PV et al. showed 1.29.

In this study betamethasone 53\% (471/889) was the most commonly used topical corticosteroid, as it is most costeffective and easily available. It is similar to the study conducted by Rathi SK et al. which showed betamethasone $58.8 \%$ as the commonest topical corticosteroid prescribed. $^{18}$ While other studies by Divyashanti CM et al, Uppal R et al and Sarvanakumar RT et al. showed clobetasol and other very high potent topical corticosteroids were common prescribed. ${ }^{19,20}$ In our study clobetasol was the second most prescribed drug. It was also observed that salicylic acid with topical corticosteroids for its keratolytic action and promotion of good penetration similar to the study by Sweileh MW et al and Khan NA et al was the most combined preparation used. $^{21}$

Mometasone, hydroquinone and tretinoin containing skinlightening formulas have recently become very popular in our country and are being marketed aggressively by numerous pharmaceutical companies to not just dermatologists but to all physicians. ${ }^{22}$ Whereas only 8 $(0.9 \%)$ were prescribed with mometasone.

Both injectable $78(10.8 \%)$ and oral $51 \quad(5.7 \%)$ preparations were prescribed only for a few patients. Dexamethasone was the only parenteral corticosteroid and among the oral corticosteroids prednisolone was only drug prescribed because of less number of drug interactions. Other study by Mirshad PV et al had same pattern of drug usage. A few prescriptions for systemic corticosteroids specifically carried instructions for administering the medication in the morning.

Drug prescribed along with corticosteroids. Our study showed that antihistamines $674(48.73 \%)$ were the most commonly prescribed systemic agents. A similar study by Padma L et al. showed antihistamines (34.69\%) were more commonly prescribed systemic drugs along with corticosteroids, because of disease symptoms coexisted with itching. ${ }^{23}$ Other important concomitant drugs used were antacids to prevent gastric irritation, calcium preparation to avoid osteoporosis and systemic antibiotics and antifungals because of presence of secondary infections. Multivitamin, iron preparation and other drugs are prescribed depending upon patient requirements.

In this study we have observed that use of dexamethasone-cyclophosphamide pulse therapy for 
pemphigus, bullous pemphigoid disease. Dexamethasone pulse therapy consists of the intravenous administration of $100 \mathrm{mg}$ dexamethasone dissolved in $500 \mathrm{ml}$ of $5 \%$ dextrose on 3 consecutive days. The pulses are repeated every 4 weeks. Cyclophosphamide $500 \mathrm{mg}$ is given as an intravenous bolus on day one as part of dexamethasonecyclophosphamide pulses (DCP) in pemphigus and other diseases, these patients also receive $50 \mathrm{mg}$ cyclophosphamide daily orally between the pulses. ${ }^{24}$

Drug usage parameters in the prescriptions was analysed and it was observed that 807 prescriptions carried 2230 drugs averaging 2.76 drugs per prescription. It was also similar to study by Sweileh MW et al (3.06), Thawani et al (2.26) and Minocha KB et (3.36). ${ }^{25,26}$ Prescriptions with polypharmacy were $9.9 \%$. It is evident that there is good deal of tendency towards polypharmacy in dermatology for the symptomatic treatment for severe and troublesome symptoms. It is preferable to keep the average number of drugs per prescription as low as possible since higher figures always lead to increased risk of drug interactions, adverse drug reactions, poor medication compliance and eventually increased cost of prescription. There are multiple definitions of polypharmacy utilized in the literature. After studying several literatures on polypharmacy here we have applied the definition of polypharmacy as the concurrent use of six or more drugs per prescription.

Usage of generic names was $69.3 \%$ and the remaining $30.7 \%$ were brand names. Studies done by Mirshad PV and Sweileh MW a study conducted in Palestine, medications were prescribed by their brand names and generic names were never preferred. Use of generic names usually provides flexibility to the dispensing pharmacist and generic drugs are less expensive than brand-name drugs. The fixed dose combinations (FDCs) prescribed were $18.4 \%$ is similar to study done by Narwane SP and lower as compared to Mirshad PV et al.

Among 2231 drugs total of 1675 (75.1\%) were prescribed from essential drug list (National List for essential Medicines of India, 2011). As per the hospital policy, all these drugs which are cheaper should be made available or the doctors should be trained to prescribe the drugs from hospital pharmacy only. Prescribing drugs from outside pharmacy increases the cost of treatment. In our study it was observed that most of these drugs were available and prescribed from the hospital pharmacy.

In our study average cost of prescription was ₹167.72. While Narwane SP et al showed average total cost per prescription was ₹ 135.60. The average hospital pharmacy cost per prescription was much lesser as compared to average outside pharmacy cost per prescription. So it is a very important factor while prescribing in a developing country like India, patient compliance is 'primarily dependent on the cost of treatment.
It is clear from this study that majority of the dermatological prescriptions were written with a thorough knowledge of the recent guidelines. The pitfalls in prescribing pattern elsewhere might be because of nonavailability of particular drugs in the hospital pharmacy or due to availability drug in particular brand names.

Since corticosteroids are one of the commonest groups of drugs used in dermatological practice, an assessment of their usage pattern is required in order to encourage their proper and rational usage. These types of studies should be recommended in order to optimize their benefits and limit their adverse effects.

\section{ACKNOWLEGMENT}

Authors would like to thank Dr. Shilpa Dastikop and Dr Gajanan Pise, department of dermatology for their guidance. Our director Dr. S.T Kalasad, for permitting us to use the college facilities. They also thank Dr Basavaraj Kotinatot, HOD of pharmacology and the staff for their advice.

Funding: No funding sources

Conflict of interest: None declared

Ethical approval: The study was approved by the Institutional Ethics Committee

\section{REFERENCES}

1. Ramsey LE. Bridging the gap between clinical pharmacology and rational drug prescribing. $\mathrm{Br} \mathbf{J}$ Clin Pharmacol. 1993;35:575-6.

2. Lamichhane DC, Giri BR, Pathak OK, Panta OB, Shankar PR. Morbidity profile and prescribing patterns among outpatients in a teaching hospital in Western Nepal. Mcgill J Med. 2006;9(2):126-133.

3. Laporte JR, Porta M, Capella D. Drug utilization studies: a tool for determining the effectiveness of drug use. Br J Clin Pharmac. 1983;16:301-4.

4. Sweileh WM. Audit of prescribing practices of topical corticosteroids in outpatient dermatology clinics in north Palestine. Eastern Mediterranean Health Journal. 2006;12:161.

5. Tadicherla S, Ross K, Shenefelt PD, Fenske NA. Topical corticosteroids in dermatology. J Drugs Dermatol. 2009;8(12):1093-05.

6. Sulzberger MB, Witten VH. The effect of topically applied compound F in selected dermatoses. J Invest Dermatol. 1952;19:101-2.

7. Kumar AM, Noushad PP, Shailaja K, Jayasutha J, Ramasamy C. A study on drug prescribing pattern and use of corticosteroids in dermatological conditions at tertiary care teaching hospital. Int $\mathbf{J}$ Pharm Sci Rev Res. 2011;9:132-5.

8. Sarkar C, Das B, Sripathi H. Drug prescribing pattern in dermatology in a teaching hospital in western Nepal. Nepal Med Assoc. 2001;41:241-6.

9. Coutinho AE, Chapman KE. The anti-inflammatory and immunosuppressive effects of glucocorticoids, 
recent developments and mechanistic insights. Mol Cell Endocrinol. 2011;335(1):2-13.

10. Divyashanti CM, Manivannan E. Prescribing analysis of corticosteroids among the dermatology in-patients in ateritary care teaching hospital, karaikal, puducherry a prospective observational study. Int J Pharm Bio Sci. 2014;5(2):324-30.

11. Bijoy KP, Vidyadhar RS, Palak P, Chintan SP, Atmaram PP. Drug prescribing and economic analysis for skin diseases in dermatology OPD of an Indian tertiary care teaching hospital: a periodic audit. Indian Journal Pharmacy Practice. 2012;5(1):28-33.

12. Mirshad PV, Afzalkhan AK, Fasalurahiman OM, Mohammed Muneersha TK. Prescription audit of corticosteroid usage in the department of dermatology at a tertiary care teaching hospital. Int $\mathbf{J}$ Basic Clin Pharmacol. 2013;2:411-3.

13. Kumar KM, Noushad PP, Shailaja K, Jayasutha J, Ramasamy C. A study on drug prescribing pattern and use of corticosteroids in dermatological conditions at a tertiary care teaching hospital. International Journal Pharmaceutical Sciences Review and Research. 2011;9(2):132-5.

14. Kuruvilla M, Sridhar KS, Kumar P, Rao GS. Pattern of skin diseases in bantwal Taluq, Dakshina kannada. Indian J Dermatol Vernereol Leprol. 2000;66(5):247-8.

15. Bufford JD, Gern JE. The hygiene hypothesis revisited. Immunol Allergy Clin North Am. 2005;25(2):247-62.

16. Jena M, Panda M, Patro N, Mishra S. Pattern of utilization of corticosteroids in department of dermatology at a tertiary care teaching hospital. Journal of Chemical and Pharmaceutical Research 2014;6(8):86-91.

17. Rathod SS, Motghare VM, Deshmukh VS, Deshpande RP, Bhamare CG, Patil JR. Prescribing practices of topical corticosteroids in outpatient dermatology department of rural tertiary care teaching hospital. Indian J Dermatol. 2013;58(5):342-5.

18. Rati S, Kumrah L. Topcal corticosteroid-induced rosacea-like dermatitis: a clinical study of 110 cases. Indian J Dermatol Venereol Leprol. 2011;77:42-6.

19. Uppal R, Sharma SC, Bhowmik SR, Sharma PL, Kaur S. Topical corticosteroids usage in dermatology. Int J Clin Pharmacol Ther Toxicol. 1999;29(2):48-50.

20. Saravanakumar RT, Prasad GS, Ragul G, Mohanta GP, Manna PK, Moorthi C. Study of prescribing pattern of topical corticosteroids in the department of dermatology of multispeciality tertiary care teaching hospital in south India. Int J Res Pharm Sci. 2012;3(4):685-7.

21. Khan NA, Abid M, Maheswari KK, Kaviarasan PK, Mohanta GP. Antibiotic prescribing pattern in department of dermatology of a teaching hospital in Tamilnadu. Indian J Pharm Pract. 2010;3(3):18-21.

22. Saraswat A, Lahiri K, Chatterjee M. Topical corticosteroid abuse on the face: a prospective, multicenter study of dermatology outpatients. Indian J Dermatol Venereol Leprol. 2011;7(2):160-6.

23. Padma L, Komala R, Madam NT, Manasa CR, Ramanujam R. Prescription trends of topical corticosteroids in dermatological condition in Dr. B. R. Ambedkar Medical College. In J Biol Med Res. 2013;4(1):2898-901.

24. Pasricha JS, Khaitan BK, Raman RS, Chandra M. Dexamethasone-cyclophosphamide pulse therapy for pemphigus. Int J Dermatol. 1995;34(12):875-82.

25. Thawani VR, Motghare VM, Dani AD and Shelgaokar SD. Therapeutic audit of dermatological prescription. Ind. J Dermatol. 1995;40(1):13-9.

26. Minocha KB, Bajaj S, Gupta K. A clinicopharmacological study of outpatient prescribing pattern of dermatological drugs in Indian tertiary Hospital. Indian J Pharmacol. 2002;32:384-5.

Cite this article as: Lamani VL, Bhushan A. Corticosteroids used in dermatology: its utilisation and cost analysis study. Int $\mathrm{J}$ Basic Clin Pharmacol 2016;5:2184-9. 